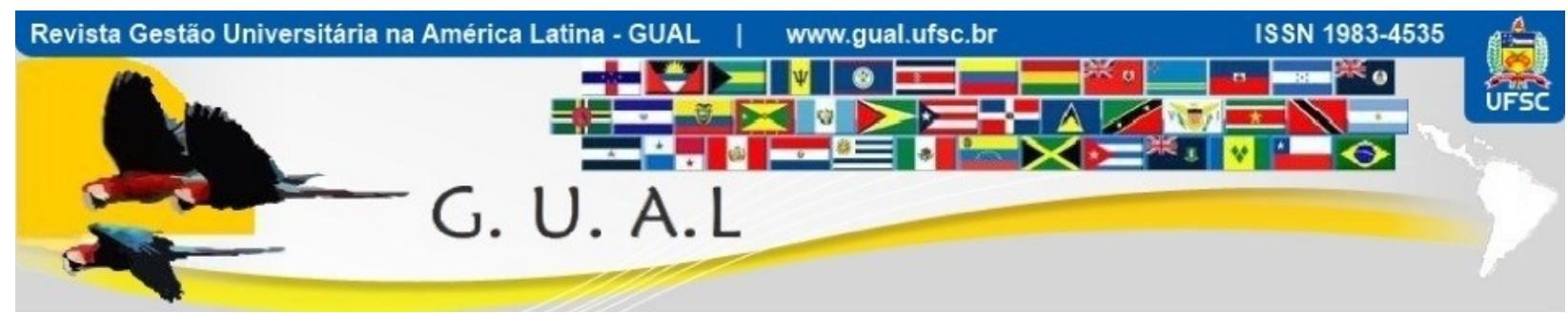

DOI: http://dx.doi.org/10.5007/1983-4535.2020v13n3p210

\title{
PLANEJAMENTO ESTRATÉGICO NO ENSINO SUPERIOR: UMA ANÁLISE DO MONITORAMENTO ESTRATÉGICO EM INSTITUIÇÕES DE SANTA CATARINA
}

\section{STRATEGIC PLANNING IN HIGHER EDUCATION: AN ANALYSIS OF STRATEGIC MONITORING IN SANTA CATARINA INSTITUTIONS}

\author{
Marília Ribas Machado, Mestre \\ http://orcid.org/0000-0002-4684-8627 \\ marilia.ribas9@gmail.com \\ Universidade do Estado de Santa Catarina | Programa de Pós-graduação em Administração \\ Florianópolis | Santa Catarina | Brasil \\ Guilherme Kalnin, Mestre \\ http://orcid.org/0000-0001-9950-5487 \\ gfkalnin@gmail.com \\ Universidade do Estado de Santa Catarina | Programa de Pós-graduação em Administração \\ Florianópolis | Santa Catarina | Brasil \\ Mario Cesar Barreto Moraes, Doutor \\ http://orcid.org/0000-0002-0760-8444 \\ mcbmstrategos@gmail.com \\ Universidade do Estado de Santa Catarina | Programa de Pós-graduação em Administração \\ Florianópolis | Santa Catarina | Brasil
}

Recebido em 26/março/2020

Aprovado em 17/julho/2020

Publicado em $01 /$ setembro/2020

Sistema de Avaliação: Double Blind Review

Esta obra está sob uma Licença Creative Commons Atribuição-Uso. 


\title{
RESUMO
}

Esse estudo se propõe a analisar o monitoramento estratégico presente nos documentos de Planejamento de Desenvolvimento Institucional (PDI) de duas instituições educacionais do estado de Santa Catarina, contrastado com a percepção de seus respectivos gestores. A pesquisa, de cunho qualitativo, procura analisar interpretativamente dois casos específicos por meio de entrevistas com os gestores responsáveis e documentos dos respectivos planejamentos institucionais. Como resultado, foi evidenciado que em ambos os casos há ausência de consenso no tocante ao documento responsável por conter as respectivas estratégias institucionais. Ademais, verificaram-se aspectos que facilitam a execução de estratégias do planejamento institucional, tais como: sistema de acompanhamento; participação das pessoas; e alinhamento entre os documentos institucionais de planejamento. Por outro lado, também destacaram-se características que dificultam a execução de estratégias, tais como: a indefinição de responsabilidades; ausência de indicadores; e resistência à mudança.

Palavras-chave: Estratégia. Planejamento Institucional. Monitoramento. Instituições de Ensino Superior.

\begin{abstract}
This study proposes to analyze the strategic monitoring of documents contained in Planejamento de Desenvolvimento Institucional (PDI) of two institutions of Santa Catarina state, contrasted with the perception of their respective managers. The qualitative research seeks to examine two specific cases interpretatively through interviews with the managers responsible and documents for the institutional planning of both cases studied. As a result, there was evidenced a wasn't a consensus about both the document responsible for containing the respective institutional strategies on both cases. Furthermore, some aspects were checked that facilitate the execution of institutional planning strategies, such as: monitoring system; involvement of people; and the alignment between institutional planning documents. On the other hand, there is also important highlight some characteristics that make it difficult the execution of institutional planning strategies, such as: undefined responsibilities; the lack of indicators; and resistance to organizational change.
\end{abstract}

Keywords: Strategy. Institutional Planning. Monitoring. Higher Education Institutions. 


\section{INTRODUÇÃO}

Desde a sua fundação, a universidade moderna possui objetivos historicamente essenciais, condensados na busca pelo desenvolvimento teórico e prático das diversas áreas do conhecimento, na disseminação de conhecimentos fundamentais e na melhoria das condições da sociedade na qual encontra-se presente (DIAS SOBRINHO, 2014). Esses objetivos norteiam todo o processo de formação das Instituições de Ensino Superior (IES), e a organização para alcance destes objetivos sintetiza o que se convém denominar gestão universitária (COLOMBO, 2004; SHATTOCK, 2003). Estes objetivos, em seu sentido contemporâneo, atribuem maiores complexidade às IES, cujas fronteiras acabam por permear o ambiente externo, e, consequentemente, remeter a necessidades estratégicas de organização e planejamento para o alcance de objetivos tanto institucionais quanto sociais (MINTZBERG; ROSE, 2007).

Neste sentido, a estratégia é observável como um plano direcionado à ação, visando lidar com as ameaças e oportunidades decorrentes em determinado ambiente em um período de tempo específico (MINTZBERG; AHLSTRAND; LAMPEL, 2010). Em poucas palavras é uma racionalização dos objetivos e respectivos modos para o seu alcance, levando em consideração a localização da organização no interior de seu ambiente, relacionando, sincronicamente, o aspecto subjetivo, relacionado à visão dos gestores, com as limitações objetivas do ambiente e da organização (MINTZBERG; ROSE, 2007). Assim, o planejamento estratégico se torna uma ferramenta essencial, por combinar aspectos instrumentais, políticos e simbólicos para o alcance de objetivos gerais e específicos, exigindo dos gestores habilidades para com os diversos aspectos presentes, no caso deste artigo, os aspectos que envolvem o lócus da gestão universitária (COLOMBO, 2004).

Salienta-se que a gestão universitária em IES deve ser atualizada, transformando valores culturais e sociais em fortes aliados do planejamento e desenvolvimento institucional. Sincronicamente, sua meta é a definição da própria realidade institucional frente ao contexto em que se encontra presente, e a manutenção das raízes históricas que fundamentam sua base essencial como educação superior (COLOMBO, 2004; ROSSETTO; LAZZARETTI; VARGAS, 2012).

Considerando a relevância dos estudos sobre o tema (ALPERSTEDT; MARTIGNAGO; FIATES, 2006; COLOMBO, 2004; ENSSLIN et al. 2016; HENN et al. 2017; Jr, PANZERI; BARBOSA, 2004; MAINARDES et al. 2011; REBECHI, 2007; 
ROSSETTO; LAZZARETTI; VARGAS 2012; TEIXEIRA et al. 2018), julga-se primordial que as instituições lidem estrategicamente com sua realidade, e, por meio de um planejamento estratégico, conheçam suas realidades e complexidades, levando em consideração suas limitações e conveniências, assim como as oportunidades e ameaças presentes em seu ambiente (MINTZBERG; ROSE, 2007).

Frente ao exposto, este artigo pretende verificar tal complexidade institucional, analisando os aspectos facilitadores e dificultadores nos planejamentos de duas IES do estado de Santa Catarina. Para tanto, analisou-se primariamente a presença de estratégias nos respectivos planos institucionais. Amplia-se então a discussão por meio da investigação de aspectos que facilitam ou dificultam a execução das estratégias de tais planejamentos, assim como as práticas de monitoramento que se fazem presentes. Assim, utiliza-se de pesquisa documental e bibliográfica, amparadas posteriormente em entrevistas com atores chave dos processos de planejamento e monitoramento do planejamento das respectivas IES.

Para o alcance deste objetivo, ressalta-se que este artigo está estruturado da seguinte forma: após a presente introdução, que contextualiza o tema de interesse e o objetivo do estudo, serão apresentados os referencias básicos que fundamentam a temática. Posteriormente, serão indicados os aspectos metodológicos as análises e apresentação dos resultados obtidos pela pesquisa, finalizado com uma exposição das considerações finais.

\section{PLANEJAMENTO ESTRATÉGICO}

É possível definir um planejamento como uma ação que possibilita o desenvolvimento de processos, técnicas e atitudes administrativas, além de proporcionar uma situação viável à avaliação, orientação e redirecionamento institucional frente a seus objetivos (Oliveira, 2008). Três são as funções que permitem a operacionalização deste planejamento, transformando-o em uma estratégia viável em seu respectivo ambiente: apoio ao processo decisório; auxílio racional às decisões; e orientar das ações institucionais (MEYER; MEYER JUNIOR, 2013).

Ao final do planejamento, tem-se então uma estratégia, capaz de oferecer vantagens competitivas futuras que têm por base as características atuais da instituição e as previsões do ambiente externo, ambas contrastadas aos objetivos institucionais (MINTZBERG; WATERS, 1985). Tal processo, segundo Mintzberg e Rose (2007), pode ser dividido em três níveis institucionais: 
- Nível estratégico, no qual são planejadas as decisões que afetam o todo da instituição;

- Nível administrativo, também conhecido como tático ou integrativo, que faz a ligação entre as decisões estratégicas e as operacionais;

- Nível operacional, em que as ações realmente acontecem. Serve para comprometer as pessoas com os planos de ações.

Em conformidade com Oliveira (2008), o planejamento em nível estratégico possui maior prazo em relação aos demais ao considerar a totalidade do conjunto formado pelos outros planejamentos institucionais, operacionalizando-os como metas para o alcance de objetivos declarados. $\mathrm{O}$ autor também enfatiza que o planejamento estratégico possui três dimensões operacionais: delineamento, elaboração; e implementação. O delineamento, envolve a estruturação do planejamento em si; da elaboração, trata da identificação das oportunidades e ameaças no ambiente para a adoção de estimativas; enquanto que, a implementação envolve os assuntos organizacionais, tais como sistema de informação, sistema orçamentário, sistema de incentivos e entre outros para fomentar o desenvolvimento de mudanças perante o planejamento estratégico.

De modo análogo, outra divisão seminal do tema é proposta por Mintzberg, Ahlstrand e Lampel (2010), os quais formulam quatro estágios essenciais à fundamentação do planejamento estratégico:

I. Fixação de objetivos: é a explicação e quantificação das metas da instituição;

II. Auditoria interna e externa: é o estudo de forças e fraquezas (incluindo a avaliação das competências distintivas), e a avaliação das condições externas da instituição (incluindo as previsões futuras dessas condições);

III. Avaliação de estratégia: é o processo de elaboração e qualificação da estratégia, onde as técnicas se afloram, como o cálculo de retorno sobre investimento, avaliação da estratégia competitiva, análise de riscos e curva de valor. Avalia-se muito a questão da criação de valor.

IV. Operacionalização da estratégia: é a reunião de um conjunto de objetivos, orçamentos, estratégias e programas que geram os planos operacionais.

Para permitir a ação de planejamento, torna-se necessário exercer controle sobre suas fases, visando monitorar o andamento das respectivas estratégias (ALPERSTEDT; MARTIGNAGO; FIATES, 2006). Este controle pode ser definido como uma ação necessária ao monitoramento das ações institucionais, analisando o alcance dos objetivos, metas e 
estratégias (MINTZBERG; AHLSTRAND; LAMPEL, 2010; MINTZBERG; ROSE, 2007). Esta ação de monitoramento pode envolver os seguintes processos:

- Estabelecer e analisar os indicadores de desempenho;

- Avaliar o desempenho dos profissionais envolvidos no processo;

- Comparar o desempenho dos profissionais envolvidos no processo;

- Analisar os desvios dos objetivos, desafios, metas e projetos estabelecidos;

- Tomar ações corretivas provocadas pelas análises efetuadas;

- Acompanhar para avaliar a eficiência e a eficácia da ação de natureza corretiva; e

- Adicionar informações ao processo de planejamento, para desenvolver os ciclos futuros da atividade administrativa (OLIVEIRA, 2008).

Ressalta-se que para a execução dos processos acima destacados, o papel dos gestores é fundamental para assegurar a realização dos objetivos institucionais. Por este motivo, a função de controle sobre o planejamento estratégico é de extrema importância para a formulação dos respectivos planos e para a orientação institucional frente a mercados cada vez mais complexos (MEYER; MEYER JUNIOR, 2013; MINTZBERG; WATERS, 1985).

\subsection{PLANEJAMENTO ESTRATÉGICO EM UNIVERSIDADES}

As universidades são instituições complexas, portadoras de objetivos, sistemas hierárquicos e estruturas diferenciadas das demais instituições burocráticas. Elas têm a função básica de promover sincronicamente três dimensões inter-relacionadas: ensino, pesquisa e extensão (COLOMBO, 2004). A complexidade de um sistema universitário pode ser constatada através de suas múltiplas funções, bem como pela diversidade de relações com seus ambientes internos e externos (DIAS SOBRINHO, 2014).

De modo análogo Kerr (2001), afirma que a universidade é em si uma multidiversidade, devido ao fato de unir diversas comunidades de objetivos diversificados. Assim a universidade se apresenta de modo:

[...] inconsistente. [Pois] não é uma simples comunidade, mas um conjunto de várias - a comunidade dos graduandos e a comunidade dos graduados; a comunidade dos humanistas, a comunidade dos cientistas sociais, a comunidade do cientista, as comunidades das escolas profissionais; a comunidade de todo o pessoal não acadêmico; a comunidade dos administradores (KERR 2001, 34, tradução nossa). 
Assim, destaca-se que a universidade é uma instituição singular, dividida em várias dimensões de análise seguindo um objetivo similar. Neste plasma, é possível um planejamento estratégico, para ordenar a conquista deste objetivo dentre as diversas comunidades persistentes no interior da instituição (COLOMBO, 2004).

O planejamento estratégico, quando praticado nas universidades, destaca então o desafio dos gestores universitários em passar do campo das ideias para a ação concreta, permeada em paradigmas (KUHN, 2013). O desafio ocorre entre racionalidade e intuição, produto e processo, intenção e ação e entre diversos outros (COLOMBO, 2004; MEYER; MEYER JUNIOR, 2013). Muitos desses conflitos estão ligados a modelos moldados para as empresas, os quais possuem uma racionalidade instrumental como premissa básica (SALAZAR, 2006; TEIXEIRA et al. 2018), cuja translocação para o campo do ensino necessita de uma adaptação para contemplar toda a complexidade da educação superior e a racionalidade substantiva que a acompanha (DIAS SOBRINHO, 2014; SAVIANI, 2010).

Entretanto, convém salientar que a utilidade do planejamento estratégico só será reconhecida caso seja traduzida em ações concretas, ou seja, caso ocorra sua implementação, devidamente acompanhada e avaliada conforme a progressão rumo aos objetivos especificados. Deste modo, os propósitos podem não ser totalmente alcançados em um primeiro ciclo, sendo necessário um controle e feedback contínuo para permitir correções, ou até mesmo a troca das estratégias e objetivos frente a uma sociedade complexa em constante mudança (COLOMBO, 2004; MINTZBERG; ROSE, 2007; REBECHI, 2007; ROSSETTO, LAZZARETTI; VARGAS, 2012; SHATTOCK, 2003).

\subsection{PLANO DE DESENVOLVIMENTO INSTITUCIONAL (PDI)}

Conforme indica Morosini (2006, 181), o PDI , que vem a condensar o planejamento estratégico em Instituições do Ensino Superior (IES), é um “[...] documento que expressa a missão da instituição de Ensino Superior e as estratégias para atingir suas metas e objetivos". Este documento abrange um período institucional de cinco anos, apresentando as respectivas metodologias para implementação dos objetivos e metas institucionais integradas em três níveis: dimensões (organização institucional e pedagógica, corpo docente e instalações); categorias de análise; e indicadores. 
Sua origem como exigência legal às instituições se relaciona à edição da Lei $\mathrm{n}^{\circ}$. 10.861, de 14 de abril de 2004, conhecida como "Lei do SINAES" ao estabelecer o Sistema Nacional de Avaliação da Educação Superior, na qual:

[...] o Ministério da Educação constatou a necessidade de introduzir como parte integrante do processo avaliativo das Instituições de Ensino Superior o planejamento estratégico, sintetizado no que se convencionou denominar plano de Desenvolvimento Institucional - PDI (MOROSINI, 2006, 182).

Em seu Artigo $1^{\circ}$, a referida Lei outorgava como finalidade sistema de avaliação recém-formado, o SINAES:

[...] a melhoria da qualidade da educação superior, a orientação da expansão da sua oferta, o aumento permanente da sua eficácia institucional e efetividade acadêmica e social e, especialmente, a promoção do aprofundamento dos compromissos e responsabilidades sociais das instituições de educação superior, por meio da valorização de sua missão pública, da promoção dos valores democráticos, do respeito à diferença e à diversidade, da afirmação da autonomia e da identidade institucional (BRASIL, 2004).

Observa-se então que a "Lei do SINAES" delimita as dimensões a serem analisadas, incluindo as adequações dos respectivos PDIs, que pretendem conferir maior eficiência e eficácia aos dispositivos contidos na LDB 9.394/96, a qual organiza o ensino superior brasileiro (BRASIL, 1996). Entretanto, a estrutura final formulada aos PDI's é outorgada pelo Decreto $n^{\circ} 5.773$, de 9 de maio de 2006, o qual altera características essenciais da avaliação de instituições e cursos do ensino superior e fundamenta as ferramentas necessárias à realização destes processos, incluindo os diversos Planos Institucionais (BRASIL, 2006). Ademais, as caracterizações deste plano variam de acordo com as Resoluções do CNE e Portarias Normativas efetivadas pelo MEC e, apesar de sua formulação livre por parte da instituição, devem possuir características específicas, afim de servir como referenciais às avaliações institucionais subsequentes (BRASIL, 2006).

O PDI se apresenta no contexto brasileiro como um documento que caracteriza as IES quanto a sua filosofia, missão, diretrizes pedagógicas e estrutura organizacional, evidenciando nestas o planejamento estratégico como ferramenta para a gestão de objetivos. Esta ferramenta, por sua vez, procura auxiliar a visão institucional a longo prazo para o atendimento das exigências legais, além de auxiliar no posicionamento institucional perante as mudanças sociais, econômicas, culturais e políticas do ambiente externo, permitindo assim uma maior interação com a sociedade em geral (SEGENREICH, 2005; SILVA; REZENDE, 2017). 
Assim, o PDI revela-se como um documento balizador das ações institucionais respectivas, porém enseja um viés regulatório, sendo obrigatória sua disponibilização por parte das instituições de educação superior.

\section{PROCEDIMENTOS METODOLÓGICOS}

A fim de alcançar o objetivo proposto, foram analisados os documentos institucionais responsáveis pelo planejamento estratégico de duas IES do Estado de Santa Catarina, quais sejam: Plano de Desenvolvimento Institucional; Plano de Gestão; Plano Anual de Trabalho; e Plano Plurianual. Ressalta-se que as Universidades objetos deste estudo, denominadas respectivamente de Alfa e Beta, foram escolhidas para o estudo por acreditar serem casos que revelam característica inerentes ao tema estudado (YIN, 2013), vide sua representatividade no contexto onde atuam.

O estudo dos documentos institucionais ofereceu suporte para uma etapa subsequente de entrevistas com os atores envolvidos no processo de acompanhamento do planejamento estratégico das respectivas instituições, oportunizando uma análise interpretativa das prática realizadas pelas mesmas, as quais possibilitaram a obtenção de dados subjetivos acerca da percepção dos envolvidos nos processos de planejamento (TRIVIÑOS, 2010).

A coleta de dados foi realizada junto aos Pró-reitores de Planejamento e Coordenadores do mesmo setor em cada IES, dependendo da viabilidade para realização das entrevistas. As entrevistas foram elaboradas com base em um roteiro semiestruturado, visando a revisão de temas referentes à construção e ao monitoramento das práticas de planejamento observadas nos respectivos PDIs.

Foram questionados 4 gestores de 2 instituições em um total de 4 entrevistas gravadas, as quais foram posteriormente transcritas para permitir sua análise. Cada respondente teve uma classificação conforme sua instituição (A e B), com um respectivo número (1 a 4) para diferenciar os dados obtidos. Esta classificação encontra-se representada na figura 1 .

Figura 1 Classificação dos respondentes

\begin{tabular}{|c|c|c|c|c|}
\hline Instituição & Respondente & Classificação & Gênero & Grau de Escolaridade \\
\hline \multirow{2}{*}{ Alfa } & 1 & A01 & Masculino & Doutor \\
\cline { 2 - 5 } & 2 & A02 & Masculino & Mestre \\
\hline \multirow{2}{*}{ Beta } & 3 & B03 & Masculino & Especialista \\
\cline { 2 - 5 } & 4 & B04 & Feminino & Graduado \\
\hline
\end{tabular}

Fonte: Elaborado pelos autores. 
Os dados obtidos a partir das entrevistas foram analisados de modo interpretativo, com base na proposta de Triviños (2010). O autor afirma que de posse das teorias, das respostas dos sujeitos obtidas permitirá ao pesquisador a elaboração de esquemas interpretativos, contendo as diversas perspectivas do fenômeno estudado. Estes fenômenos, em seu caráter subjetivo, permitem ao investigador observar divergências, conflitos, vazios e pontos coincidentes nas afirmações dos entrevistados, apoiada em três aspectos fundamentais:

I. Nos resultados alcançados no estudo (respostas aos instrumentos, ideias dos documentos etc.);

II. Na fundamentação teórica (manejo dos conceitos-chaves das teorias e de outros pontos de vista); e

III. Na experiência pessoal do investigador (TRIVIÑOS, 2010).

Cabe ressaltar também que, pelo fato da pesquisa caracterizar-se como exploratória, utilizando-se de dados primários, consequentemente atrelados a uma perspectiva indutiva, as conclusões emergentes são de difícil generalização, mantendo-se no campo do particular e específico (CRESWELL, 2014; TRIVIÑOS, 2010). Acredita-se que esta pesquisa possa vir a embasar hipóteses posteriores quanto à gestão de instituições do ensino superior, ampliando o escopo do debate atual da área.

\section{ANÁLISE E APRESENTAÇÃO DOS DADOS}

Neste tópico pretende-se analisar o processo de monitoramento das estratégias institucionais a partir das entrevistas realizadas com gestores responsáveis pelos respectivos planejamentos estratégicos institucionais, visando expor suas reflexões acerca: do documento estratégico institucional; do processo de monitoramento estratégico utilizado; e demais fatores intrínsecos ao processo de acompanhamento estratégico institucional.

\subsection{PRESENÇA DE ESTRATÉGIAS NOS CASOS PESQUISADOS}

Ao analisar os documentos específicos da instituição Alfa, observou-se a existência de três documentos principais: Planejamento Estratégico (Plano 20), cujo período de vigência corresponde de 2005 até 2025; Plano de Gestão, com período de vigência de 2016 a 2020; e o Plano de Desenvolvimento Institucional (PDI), com vigência de 2017 a 2021. O entrevistado A01 reforça a existência e importância dos três instrumentos na Instituição quando comenta que: 
Nós temos três instrumentos: O Plano Estratégico, o PDI e o Plano de Gestão, que é o documento mais forte atualmente que tem as metas, métricas e apuração mensal ou bimestral e é o documento que utilizamos para nortear nossas ações. O Plano Estratégico é o mais etéreo. O PDI é o documento mais institucional, voltado principalmente para pró-reitoria de pesquisa e pós-graduação e criação novos cursos. (A01).

O principal documento que prevê diretrizes de acompanhamento das estratégias internas da instituição é denominado pelos entrevistados como "Plano de Gestão" e possui uma vigência de 5 anos, sendo o último reiterado no período de 2016, válido até 2020. Este documento, segundo os entrevistados A01 e A02, foi elaborado com o intuito de colaborar com a operacionalização das estratégias do quadriênio correspondente. O Plano apresenta propostas baseadas nos eixos de inovação, relacionamento e sustentabilidade, visando um desenvolvimento institucional nas áreas tanto administrativas quanto essenciais, envolvendo ensino, pesquisa e extensão.

$\mathrm{Na}$ Instituição Beta, observou-se que as estratégias institucionais se encontram representadas em dois documentos: em seu PDI, sendo o último com vigência de 2015 a 2019. Este documento apresenta tanto as estratégias quanto as respectivas diretrizes de acompanhamento e manutenção das estratégias ao período vigente ao plano; e em um Planejamento Anual, contendo metas e ações planejadas pelas Unidades Universitárias e Administrativas que compõem a Universidade, realizado anualmente e constantemente avaliadas pela própria instituição.

Frente ao exposto, apesar da literatura prever que o PDI deve ser o documento responsável por conter as estratégias que visam alcançar metas e objetivos institucionais, não se observa uma regra única à sua utilização, sendo possível a interpretação dos gestores e de sua respectiva comunidade acadêmica para compor os respectivos documentos. À vista disso, foi possível perceber que em ambos os casos há uma ausência de consenso sobre o documento responsável por conter as estratégias institucionais.

\subsection{MONITORAMENTO DAS ESTRATÉGIAS NOS CASOS PESQUISADOS}

De acordo com as entrevistas realizadas com os gestores de ambas as instituições, verificou-se que a instituição Alfa realiza o acompanhamento de modo manual, sem um software específico, utilizando métricas e indicadores constituídos a priori em seus respectivos planos, porém, com plena consciência da necessidade de reflexão sobre os mesmos no decorrer das ações estratégicas. Ao serem indagados, o gestor A02 afirmou que 
"O acompanhamento é realizado com a utilização de planilhas no Excel. As metas e os objetivos de cada ação dos projetos são colocados em um quadro com post its" (Entrevistado A02). Ou seja, esta instituição se utiliza de métodos simples, porém indicados como efícazes à disseminação e manutenção de tarefas e responsabilidades, algo retratado tanto pelos entrevistados A01 quanto A02.

Por outro lado, os gestores da instituição Beta afirmaram que era o primeiro ano que utilizavam um sistema para auxílio do monitoramento de estratégias, indicando que: "Iniciamos este ano a realização do monitoramento por meio de um sistema. Todos os [colaboradores] podem inserir e acompanhar todos os projetos desenvolvidos da instituição" (Entrevistado B03). Segundo as entrevistas realizadas com os gestores B03 e B04, a utilização deste software específico ampliou as perspectivas e procedeu a uma economia de tempo aos interessados no planejamento estratégico, vide compor informações de maneira mais clara e rápida que os métodos manuais anteriormente utilizados.

Ressalta-se, porém, que tanto os gestores da instituição Alfa quanto os gestores da instituição Beta possuem opiniões convergentes no sentido de não acreditar que a presença de um sistema de monitoramento será uma solução última para o monitoramento das estratégias institucionais. Tal característica é observável nas falas do gestor B04, quando afirma que: “O sistema existe, entretanto, falta definir os indicadores de acompanhamento para mensurar o alcance dos objetivos e metas" (Entrevistado B04). De modo análogo, o gestor A02 da Instituição Alfa afirma que toda a cultura institucional deve estar presente e voltada ao processo de planejamento para garantir seu funcionamento eficaz e eficiente, ao comentar que: "O mais importante é convencer as pessoas de que tem que fazer planejamento. $\mathrm{O}$ sistema pode ajudar, mas primeiro tem que ter a cultura do planejamento e do acompanhamento na instituição para depois criar um sistema adequado" (Entrevistado A02).

Infere-se, portanto, que há entre as instituições fragilidades intrínsecas tanto ao processo de planejamento quanto ao processo de monitoramento das estratégias institucionais. Essas fragilidades podem ser explicadas em razão das instituições de ensino superior serem caracterizadas como instituições singulares, uma vez que dependem da aceitação e legitimação de suas ações junto aos seus atores relevantes (ALPERSTEDT; MARTIGNAGO; FIATES, 2006). 


\subsection{ASPECTOS QUE FACILITAM E DIFICULTAM A EXECUÇÃO DE ESTRATÉGIAS INSTITUCIONAIS}

Neste tópico, serão esboçados alguns dos aspectos encontrados pela pesquisa que facilitam ou dificultam a execução do planejamento estratégico nas Instituições trabalhadas. Ressalta-se que muitos dos gestores entrevistados forneceram respostas similares em ambos os aspectos.

Em relação aos aspectos facilitadores, as respostas mais recorrentes foram: a presença de um sistema de acompanhamento; um engajamento e participação coesos entre os atores; a existência de uma cultura de planejamento sem rupturas; e um alinhamento entre todos os documentos institucionais de planejamento. No tocante aos aspectos dificultadores, as afirmações mais recorrentes foram: a ausência de um sistema para auxiliar o acompanhamento das estratégias; a falta de clareza nas metas; a criação de indicadores de difícil mensuração; a resistência institucional à mudança dos diversos atores; e a dificuldade de sensibilização destes atores.

\subsubsection{Aspectos facilitadores}

Tendo em vista as reflexões dos gestores das duas instituições no tocante aos aspectos que facilitam a execução das estratégias institucionais, foi possível inferir que o engajamento e a participação das pessoas nos processos administrativos, introduzindo um embasamento democrático ao processo, auxilia a instituição tanto no desenvolvimento de seus objetivos e metas quanto no acompanhamento das estratégias criadas e realizadas. Esta característica encontra-se presente no imaginário da Instituição Alfa, quando o gestor A02 indica que: "O que ajuda muito é a equipe estar engajada na execução do plano, [pois] o objetivo dos [gestores] é conseguir alcançar essas metas e objetivos" (Entrevistado A02).

O outro gestor da instituição, A01, de modo análogo, indica que uma característica facilitadora de alto impacto é o alinhamento entre os documentos institucionais, quando comenta que: "[O] alinhamento entre os documentos de gestão da instituição são importantes porque eles conduzem a universidade a alcançar os objetivos planejados" (Entrevistado A01). Os dois gestores da instituição Beta (B03 e B04) declararam que a ferramenta de acompanhamento de auxilia o processo em todas as suas etapas, designando a este um caráter de "[...] facilitador para o acompanhamento, haja vista que por meio deste sistema podem-se gerenciar de maneira eficaz os projetos desenvolvidos pela instituição”. Entretanto, deve-se 
atentar para o estabelecimento de metas claras para acompanhar tais sistemas, além de estruturar prazos e denominar responsáveis a priori, conforme indicado pelo gestor A01: "Deve-se estabelecer metas claras com relação ao responsável, ao prazo e [de modo] entregável e palpável" (Entrevistado A01), sendo necessário, deste modo: "Criar indicadores por metas e objetivos, e se possível vinculá-las ao orçamento das [respectivas] unidades" (Entrevistado B02)

Sob esse ponto de vista, cabe ressaltar que a literatura também indica uma aproximação de sistemas de apoio ao monitoramento de estratégias como facilitadores, onde autores como MINTZBERG; AHSTRAND; LAMPEL (2010), por exemplo, indicam que estes sistemas atribuem uma melhor percepção aos gestores das atividades institucionais, atribuindo a estes uma maior possibilidade de controle.

Outro aspecto abordado em relação ao ponto forte da equipe é a multidisciplinaridade o que possibilita a solução de demandas com uma maior amplitude de perspectivas e olhares, atribuindo diversos paradigmas de interpretação aos problemas institucionais (BASTOS; GONDIM; LOIOLA, 2004; OLIVEIRA, 2008). Este aspecto é observável nas falas dos respondentes, quando comentam que: "A multidisciplinaridade da equipe também é vista como um ponto forte. Temos economistas, administradores, engenheiros trabalhando juntos na mesma equipe" (Entrevistado A01).

Uma formação variada às equipes foi outro ponto de destaque como facilitador do processo de planejamento estratégico, pois, sob o ponto de vista tanto dos entrevistados quanto da literatura especializada, esta característica provém uma complementaridade às ações entre os diversos participantes do processo de planejamento e execução das estratégias, vide que, segundo um dos entrevistados: "[...] uma equipe complementar [...] produz um resultado melhor". (Entrevistado A02). Foi também ressaltado por todos os entrevistados que a presença de pessoas com os mais diversos conhecimentos é uma forma de ampliação do conhecimento, reduzindo a fragmentação existente no campo da gestão universitária.

Um ponto de importância, citado brevemente pelos entrevistados da Instituição Alfa (A01 e A02), é a necessidade de um processo de continuidade dos projetos estratégicos, indicando a necessidade de um alinhamento da cultura institucional entre documentos e colaboradores, tal como esboçada pelo gestor A02 quando comenta que: "Esse alinhamento entre os documentos de gestão da instituição é importante porque são eles que conduzem a universidade ao alcance dos objetivos planejados". 
Diante do exposto, observou-se nos casos abordados que as principais características que facilitam a execução de estratégias no planejamento institucional remetem principalmente à coesão entre os atores, delineando o impacto presente da gestão dos diversos recursos humanos da instituição para o fomento da complementaridade entre perspectivas e ações, assim como a fundamentação de sistemas que permitem um monitoramento e controle da situação institucional atual. De modo análogo, observou-se que os aspectos citados pelos gestores se encontram em consonância com o embasado na literatura científica da área, demonstrando uma complementaridade entre prática e teoria.

\subsubsection{Aspectos dificultadores}

A partir dos dados obtidos, foram observadas diversas características que dificultaram, na visão dos gestores entrevistados, os processos de monitoramento e execução das estratégias. As principais alusões referiram-se ao comportamento dos colaboradores e ao processo de envolvimento dos mesmos, afim de formar uma cultura específica ao cumprimento das estratégias, ou seja, não comportando uma dificuldade propriamente institucional. Este fato é abordado, por exemplo, pelo entrevistado A02, quando comenta que: “Às vezes, as dificuldades encontradas ocorrem em função dos servidores priorizarem seus interesses pessoais acima dos interesses da instituição" (Entrevistado A02). Pois, tal como indica o Entrevistado 01:

Se não tem sensibilização [os colaboradores] recebem um pacote de metas e agem de maneira que não entendem o como fazer descrito pelo superior. Esse trabalho de estar constantemente educando, sensibilizando as pessoas, fazendo as pessoas participarem do acompanhamento, mas em especial no estabelecimento das metas é bem importante para a instituição.

O mesmo gestor também argumenta que "Se você não vê os objetivos estratégicos como uma parcela de sua responsabilidade, ou se você não se percebe naquelas ações, no resultado que se colhe do alcance desses objetivos você não tem o engajamento dos [colaboradores]" (Entrevistado A02). Este fator é observado na literatura, ao verificar a necessidade de participação, de modo a outorgar um caráter democrático e de envolvimento ao processo estratégico da instituição, processo esse que necessita principalmente de atenção a caracteres relacionados a motivação e engajamento (HAMEL; PRAHALAD, 2005; MINTZBERG; AHLSTRAND; LAMPEL, 2010). 
Outro ponto elencado nas entrevistas, de modo assíduo, foi a resistência à mudança presente em ambas as instituições. Conforme o gestor A02: "Muitas pessoas gostam de ficar em suas rotinas e quando elas são confrontadas com alguma mudança organizacional elas resistem. Não por alguma questão externa, mas sim, [apenas] por resistência à mudança" (Entrevistado A02). Esta característica é verificada na literatura, a qual tende a indicar que as IES apresentam algumas das maiores resistências à mudança ou transformações exigidas pelo ambiente (COLOMBO, 2004; MEYER; MEYER JUNIOR, 2013). Outra dificuldade, elencada pelo entrevistado B03, condiz à ausência de metas e objetivos claros e mensuráveis, ao apontar que: "A maior dificuldade encontrada está na falta de metas e objetivos claros e mensuráveis, o que resulta na impossibilidade de criação de indicadores eficientes" (Entrevistado B03).

A ausência de um sistema foi elencada pelo entrevistado B02, como segue: "O que mais dificultou o acompanhamento eu acho que é a falta de um sistema, [...] de problema físico, esse é o [principal] problema. A falta dele acaba tornando a atividade de acompanhamento muito penosa" (Entrevistado B02). Algo análogo é indicado pelo gestor A01, ao comentar que: "O principal dificultador é ausência de uma ferramenta de acompanhamento" (Entrevistado A01).

Um fator crucial indicado pelas entrevistas foi a falta de indicadores e metas quantificáveis para o acompanhamento das estratégias contidas nos planos, ao confundir os diversos participantes e diminuir a eficiência do sistema formado, pois, como cita o gestor A02: "A maior dificuldade encontrada está na falta de metas e objetivos claros e mensuráveis, o que resulta na impossibilidade de criação de indicadores eficientes. Por isso a importância de definir metas claras para que os servidores percebam a necessidade de rever as metas e ações como sendo importantes para a instituição" (Entrevistado A02)

Outro aspecto negativo abordado pelos gestores das instituições relaciona-se à inexperiência dos gestores e colaboradores. A fim de corroborar com esse posicionamento, o entrevistado A02, ao apontar este problema como uma ampla barreira contemporânea na instituição Alfa, devido às trocas de colaboradores responsáveis ao planejamento estratégico, salienta que: "Hoje ainda a equipe não está solidificada, há ainda servidores recém-chegados no setor" (Entrevistado A02) Seguindo a perspectiva da falta de experiência, outro entrevistado (B02) abordou essa mesma perspectiva ao dialogar que: "Existe a falta de 
experiência na área, uma vez que nenhum dos servidores da equipe já trabalhou na área de planejamento previamente, nem mesmo em outra instituição" (Entrevistado B02).

A partir do exposto, as principais dificuldades elencadas pelos gestores entrevistados caracterizam-se principalmente em dois grupos: o primeiro é a falta de organização, que convém à indicadores ou metas que dificultam o controle ou a dificuldades sistêmicas no processo de elaboração e execução da estratégia; o segundo fator convém a resistência à mudança, pautada principalmente em caracteres subjetivos dos diversos atores que traduzem o plano à prática.

\subsection{PORPOSTAS DE ENCAMINHAMENTO DOS RESULTADOS DA PESQUISA}

Como resultado, expõem-se alguns conjuntos de alternativas para melhoria no monitoramento das estratégias institucionais, tais que se evidenciaram como contundentes à prática dos gestores entrevistados em ambas as IES (Alfa e Beta):

a) Institucionalizar uma cultura de planejamento, de modo que a fomentar este como algo agregador às rotinas dos diversos colaboradores;

b) Construir objetivos estratégicos que especifiquem claramente as metas, ao mesmo tempo que se delineiam os responsáveis tanto pela execução quanto monitoramento, assim como a determinação de prazos específicos para cada meta e objetivo;

c) Buscar o pleno alinhamento dos objetivos estabelecidos nos diversos planos, setores e cursos com os objetivos e estratégias gerais da instituição;

d) Garantir a integração do planejamento nos processos organizacionais e garantir sua revisão constante nas práticas e processos diários;

e) Utilizar sistemas de monitoramento para auxiliar na análise dos quadros atuais da instituição, com o intuito de simplificar e dinamizar o acompanhamento estratégico;

f) Constituir uma equipe multidisciplinar ao pelo acompanhamento e execução das estratégias, outorgando-os autonomia suficiente a classificar, avaliar e mensurar o andamento das atividades realizadas.

Cabe salientar que as entrevistas, possibilitaram a identificação de pontos específicos de atenção a gestores diversos. Entretanto, não se fazem aqui ramificação rígidas à prática de planejamento estratégico, sendo necessário a seus gestores uma análise de seu contexto e possibilidades, afim de emergir deste as ferramentas ideias para o trabalho e desenvolvimento institucional. 
Por fim, o aspecto de maior destaque nas entrevistas, o qual deve ser abordado com maior expressão pelos gestores de IES, é a relação de profissionalização da gestão necessária à atuação institucional, ou seja, a institucionalização de uma cultura de planejamento, que sensibilize os colaboradores a trabalhar com ferramentas gerenciais, além de objetivos, metas e técnicas administrativas como alternativas complementares a seus processos diários, tendo em vista um desenvolvimento institucional sistêmico sem aversão à mudança organizacional, tal como esboçado na literatura clássica da área (COLOMBO, 2004; ESTRADA; ALMEIDA, 2007; EYNG, 2004).

\section{CONSIDERAÇÕES FINAIS}

Esta pesquisa procurou identificar e analisar estudo analisar o processo de monitoramento estratégico exposto nos documentos de Planejamento de Desenvolvimento Institucional (PDI) de duas Instituições de Ensino Superior do Estado de Santa Catarina. O estudo partiu dos conceitos macro teóricos de planejamento estratégico para uma perspectiva do planejamento no ambiente universitário evidenciando através de teóricos que abordam essa temática, seus efeitos, contradições e observações. Em um segundo momento, houve uma etapa endereçada junto aos Pró-reitores de Planejamento e Coordenadores do mesmo setor em cada IES, com o objetivo de clarificar, através de seus conhecimentos empíricos, quais os fatores que facilitam ou dificultam os processos de monitoramento e elaboração do planejamento estratégico, bem como outros fatores intrínsecos ao processo de acompanhamento estratégico nas instituições abordadas.

Diversos autores fazem considerações sobre como deve acontecer o processo de planejamento e monitoramento das estratégias presentes nos planejamentos institucionais das IES. Entretanto, apesar da existência de diversos instrumentos, observou-se como resultado desta pesquisa que apenas o apoio de ferramentas gerenciais não é determinante ao monitoramento ou alcance efetivo das estratégias e objetivos institucionais, pois além dos aspectos instrumentais, também se encontram presente caracteres políticos e simbólicos, necessários ao envolvimento dos diversos atores institucionais.

Dessa maneira, foi possível perceber os aspectos obtidos nas entrevistas produziram orientações similares. Dentre os temas recorrentes que os gestores citaram foram: o uso de um sistema como facilitador do acompanhamento do planejamento das instituições; o estabelecimento de metas, prazos e pessoas responsáveis por cada objetivo estratégico da 
instituição e também a profissionalização da gestão, ou seja, o trabalho através de metas, planejamento e processos administrativos como fontes para um melhor aporte aos processos envolventes da estratégia institucional.

Salienta-se ainda que os aspectos facilitadores e dificultadores de execução das estratégias convergem não somente a aspectos instrumentais, mas também a características subjetivas que envolvem a gestão de um contexto complexo. Assim, convém salientar que todas as características aqui abordadas, desde a institucionalização de processos e métricas até a alteração de paradigmas e perspectivas, convém à constituição de uma cultura própria ao planejamento, que necessita dos gestores a arte de lidar com processos racionais e não racionais envolvendo os diversos atores institucionais, uma vez que as IES centram-se sob o conhecimento e manifestam peculiaridades, diferenciando-as da administração em seu modus operandi puramente empresarial (COLOMBO, 2004; DIAS SOBRINHO, 2014; MEYER; MEYER JUNIOR, 2013)

Frente ao exposto, destaca-se que as instituições e seus gestores devem estar atentos ao tipo de abordagem que desejam se inspirar, seja esta administrativa, remetendo aos caracteres de eficácia e eficiência (COLOMBO, 2004; ENSSLIN et al. 2016; MEYER; MEYER JUNIOR, 2013), ou pedagógica, relacionada à melhoria de qualidade em seu sentido transformador (CHENG, 2014; FILIPPAKOU, 2011; HARVEY; NEWTON, 2004). Assim, convém considerar que, embora as IES possuam objetivos que muitas vezes se encontram diluído em seu complexo contexto, seu principal objetivo é realizar sua função social, ao contribuir efetivamente para a produção, transmissão e aplicação de conhecimentos, beneficiando a sociedade que lhe confere sentido.

\section{REFERÊNCIAS}

ALPERSTEDT, G. D.; MARTIGNAGO., G.; FIATES, G. S. "O Processo de Adaptação Estratégica de Uma Instituição de Ensino Superior Sob a Ótica Da Teoria Institucional." Revista de Ciências da Administração 8(15): 1-24, 2006.

BASTOS, A. V. .; GUEDES, S. M.; LOIOLA, E. “Aprendizagem Organizacional versus Organizações Que Aprendem: Características e Desafios Que Cercam Essas Duas Abordagens de Pesquisa." Revista de Administração da USP 39(3): 220-30, 2004.

BRASIL. "Lei N 9.394, de 20 de Dezembro de 1996. Estabelece as Diretrizes e Bases Para a Educação Nacional." Diário Oficial da República Federativa do Brasil.

BRASIL. Lei Nº 10.861, de 14 de Abril de 2004. Institui o Sistema Nacional de Avaliação Da 
Educação Superior e Da Outras Providências. Diário Oficial da República Federativa do Brasil.

BRASIL. Decreto N ${ }^{0}$ 5.773, de 09 de Maio de 2006. Dispõe Sobre o Exercício Das Funções de Regulação, Supervisão e Avaliação de Instituições de Educação Superior e Cursos Superiores de Graduação e Seqüenciais No Sistema Federal de Ensino. Diário Oficial da República Federativa do Brasil.

CHENG, Ming. Quality as Transformation: Educational Metamorphosis. Quality in Higher Education 20(3): 272-89, 2014.

COLOMBO, Sonia Simões. Gestão Educacional: Uma Nova Visão. Porto Alegre: Bookman, 2004.

CRESWELL, J. W. Research Design: Qualitative, Quantitative \& Mixed Methods Approaches. 4 ${ }^{\mathrm{a}}$. Thousand Oaks: SAGE Publications, Inc., 2014.

SOBRINHO, J. D. Universidade e Novos Modos de Produção, Circulação e Aplicação Do Conhecimento. Avaliação: Revista da Avaliação da Educação Superior 19(3): 643-62, 2014.

ENSSLIN, Sandra Rolim., et al. Gestão Universitária: Identificação e Análise Dos Indicadores Utilizados Na Literatura. Contextus 14(3): 14-3, 2016.

ESTRADA, R. J. S.; MARTINHO, I. R. A. A Eficiência e a Eficácia Da Gestão Estratégica: Do Planejamento Estratégico à Mudança Organizacional. Revista de Ciências da Administração 9(19): 147-78, 2007.

EYNG, Ana Maria. Avaliação e Identidade Institucional: construindo uma cultura de antecipação. Revista Diálogo Educacional 4(11): 33-42, 2004.

FILIPPAKOU, Ourania. The Idea of Quality in Higher Education: A Conceptual Approach. Discourse: Studies in the Cultural Politics of Education 32(1): 15-28, 2011.

HAMEL, G.; C. K. PRAHALAD. Competindo Pelo Futuro. Rio de Janeiro: Campus, 2005.

HARVEY, Lee.; JETHRO Newton. Transforming Quality Evaluation. Quality in Higher Education 10(2): 149-65, 2004.

HENN, S. A., et al., Planejamento Estratégico de Uma Instituição de Ensino Superior Federal Brasileira: Uma Análise à Luz Do Movimento Da Governança Pública. Organizações em Contexto 13(25): 219-43, 2017.

JR, A. C.; PANZERI, V..; BARBOSA, A. A. O Planejamento Estratégico Das Instituições de Ensino Superior a Partir de Referenciais Competentes. Revista de Administração da UNIMEP 2(3): 48-58, 2004.

KERR, Clark. The Uses of University. 5 . Massachusetts: Harvard University Press, 2001. 
KUHN, Thomas S. A Estrutura Das Revoluções Científicas. 12ª . São Paulo: Perspectiva, 2013.

MAINARDES, E. W., MIRANDA, C. S., CORREIA, C. H. A Gestão Estratégica de Instituições de Ensino Superior: Um Estudo Multicaso.” Contextus 9(1): 19-32, 2011.

MEC. (2007). "Instruções Para Elaboração de Plano de Desenvolvimento Institucional (PDI).” SAPIEnS. http://www2.mec.gov.br/sapiens/pdi.html (July 18, 2018).

MEYER, B.; MEYER JUNIOR,V. Managerialism na Gestão Universitária: Uma Análise de Suas Manifestações Em Uma Instituição Empresarial. Revista Gestão Universitária na América Latina - GUAL 6(3): 1-20, 2013.

MINTZBERG, H.; AHLSTRAND, B.; LAMPEL, J. Safári de Estratégia: Um Roteiro Pela Selva Do Planejamento Estratégico. 2a . Porto Alegre: Bookman, 2010.

MINTZBERG, H.; ROSE, A. Strategic Management Upside Down. In Tracking Strategies, ed. H. Mintzberg. New York: Oxford University Press, 283-317, 2007.

MINTZBERG, H.; WATERS, J. A. Of Strategies, Deliberate and Emergent. Strategic Management Journal 6(1): 257-72, 1985.

MOROSINI, M. C. Enciclopédia de Pedagogia Universitária. Brasília: INEP/MEC, 2006.

OLIVEIRA, Djalma de Pinho Rebouças. Planejamento Estratégico: Conceitos, Metodologias e Prática. São Paulo: Atlas, 2008.

REBECHI, R. O Planejamento Estratégico nas Instituições de Ensino Superior dos Cursos de Administração do Estado de São Paulo. Revista de Administração da UNIMEP 5(3): 10112, 2007.

ROSSETTO, C. R.; LAZZARETTI, K.; VARGAS, S. M. L. Adaptação Estratégica Em Uma Instituição de Educação Profissional. Revista de Administração FACES II (2): 108-29, 2012.

SALAZAR, J. N. A. Estratégia Organizacional e Empreendedorismo. Organizações em Contexto 2(4): 196-214, 2006.

SAVIANI, D. História Das Ideias Pedagógicas No Brasil. $3^{\mathrm{a}}$. Campinas, SP: Autores Associados, 2010.

SEGENREICH, S. C. D. O PDI como Referente para Avaliação de Instituições de Educação Superior: lições de uma experiência. Ensaio: Avaliação e Políticas Públicas em Educação 13(47): 149-67, 2005.

SHATTOCK, M. Managing Successful Universities. Berkshire: Open University Press, 2003. 
SILVA, C. M. M.; REZENDE, J. F. C. Geração de Valor No Ensino Superior Privado: Uma Análise Do Plano de Desenvolvimento Institucional (PDI). Contextus 15(3): 66-90, 2017.

TEIXEIRA, L. I. L. et al., Governança Em IFES Do Nordeste: Concepção, Execução e Monitoramento Da Gestão Estratégica. Organizações em Contexto 14(28): 265-91, 2018.

TRIVIÑOS, A. N. S. Introdução à Pesquisa Em Ciências Sociais: A Pesquisa Qualitativa Em Educação. São Paulo: Atlas, 2010.

YIN, Robert K. Case Study Research: Design and Methods. $5^{\mathrm{a}}$. California: SAGE Publications Inc, 2013. 